\title{
Critical analysis about solutions and models of solar shades in non-residential buildings from tropical regions.
}

\author{
Castañon. J.A.B., Caldeira, L.F.D., Gervásio, M.F., Brum, F.M. \\ Mestrado em Ambiente Construído, Departamento de Engenharia, Universidade Federal de Juiz de Fora, \\ Campus da UFJF, 4 a Plataforma do Setor de Tecnologia, Bairro Martelos, MG, Brasil.
}

\begin{abstract}
Whereas the non-residential buildings consume a significant percentage of the total energy produced by the city, is important that these buildings have for such consumption is reduced or consumed in a conscious way. To do so, using concepts of energy efficiency, this work is to explain passive strategies with the use of flexible solar shades that help to get a favorable outcome with respect to the performance of the building right in the initial stages of planning and design. Once initial gains can be obtained and the architecture constants that value at the same time provide better working conditions and indoor comfort.
\end{abstract}

Keywords: energy efficiency, passive strategies, solar shades.

Considering that the consumption of electricity in non-residential buildings accounts for more than $35 \%$ of the total energy produced to power a city and those buildings are responsible for issuing about $33 \%$ of $\mathrm{CO}_{2}$ emissions in the atmosphere [1], it is necessary to improve the study of passive strategies incorporated into architectural designs, new or existing, so can appreciate more a tool that helps in reducing the environmental impact by industry and therefore increase the comfort of users without requiring huge investments and greater complexity.

The shields are important solar passive architectural elements that assist in reducing or filtering the excessive incidence of natural lighting within buildings, especially in situations close to the tropics. In addition, they can significantly enhance the decrease in demand for air conditioning in artificial environments, as the use of them allied to architectural design. However, some solutions adopted may also reduce the visual comfort and increase the consumption of artificial lighting, so such situations should be considered throughout the design process so that the effectiveness of the solution is reached [2].

On the one hand, can be observed benefits and limitations related to project performance with regard to its architectural features, on the other hand can also be identified advantages over the application ergo- nomic, as well as in a research produced by [3] they report that these instruments are an important part in the project strategy to achieve increased business and improved productivity and quality of well-being of employees.

According to [4] report that demand for electrical energy consumed by these non-residential buildings accounts for almost $40 \%$ of the total energy produced in U.S. cities. With this, the government initiated new requirements for sustainable energy consumption in public buildings and the project to include such benefits in new buildings from 2020. The project should include concepts of sustainability and energy efficiency from the design process, step through the construction, operation and management, maintenance and deconstruction.

According to [5], the performance and productivity of the activities within the environment of nonresidential buildings are directly related to the factors of thermal and luminous comfort. So, this is an important data that should also be considered during the design process. So there should be a greater integration between the professionals of the construction industry to directly reach the beginning of project design.

This work interest in the study of solar shades that provide a more adequate amount of natural light re- 
quired and reduce the cost of energy consumption. The fact make use of sunlight measured, it also draws attention to the use of this concept allied to architecture. Some published examples already do not serve effectively to all requests, due to the fact that constrain some different circumstances, like sunny days or cloudy days, which leads the user to continue to resort to artificial solutions.

According to research conducted by [2], were analyzed four formats of solar shades. Each request directed to a demarcated by the analysis of local climate. Some combinations types are also mentioned. However, all dealing with fixtures, or have restrictions on the malleability of positions that allow the efficiency of the tool throughout the day and adapting to climate throughout the year. Thus, were highlight the importance of developing studies in order to get more adaptability of models, as we see in examples already deployed in Brazil.

Below are shown the four models studied by [2]. In them you can recognize the effect caused by passive solutions incorporated into the project.

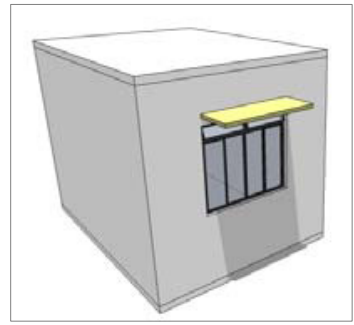

Figure 1: Model 01 - Boss simple. Source: Personal File, 2011

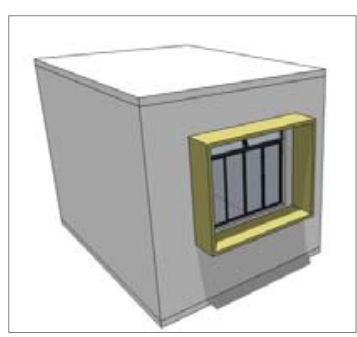

Figure 2: Model 02 - Boss simple rectangular side flaps. Source: Personal File, 2011.

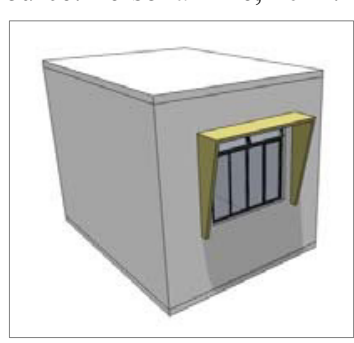

Figure 3: Model 03 - Boss simple triangular side flaps. Source: Personal File, 2011.

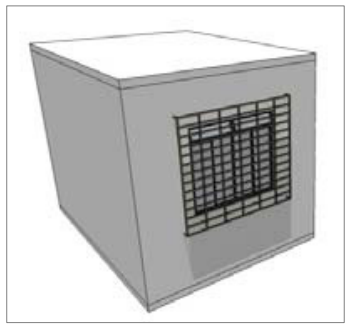

Figure 4: Model 04 - Boss continued. Source: Personal File, 2011.

In the tropics are already found solutions as suggested by [2] since the early 1980's. Is the case of Gustavo Capanema building, Ministry of Education and Culture of Rio de Janeiro, where the two models were used, but one is already flexible in the horizontal position (see figures 5 and 6). Other example is the building Banco do Brasil, in Juiz de Fora, that the same case can be observed with vertical fins (see figure 7).

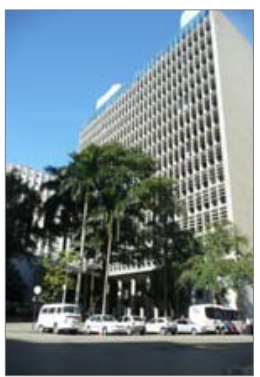

Figure 5: Building Gustavo Capanema, Rio de Janeiro. Costa's plan. Source: panoramio.com

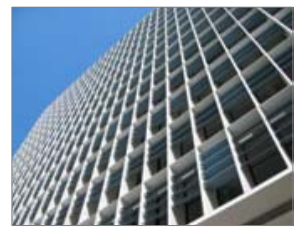

Figure 6: Detail of the building shields Gustavo Capanema, Rio de Janeiro. Costa's plan.

Source: hotelrafael.wordpress.com

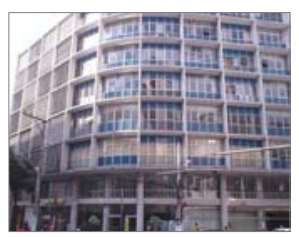

Figure 7: Building the Bank of Brazil, Juiz de Fora. Designed by Oscar Niemeyer. Source: imageshack.us 
Although important analysis performed by the authors mentioned, it is assumed to be more consistent studies on flexible and appropriate proposals for the shown conditions.

The following figures are exemplified in a study that models can be better used or incorporated into architectural designs. Some options are suggestions of evolutionary models presented above correspond to proposals and other new ones.

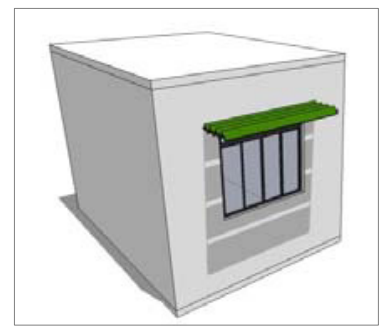

Figure 8: Model 05 - Brises mobile horizontal instead of simple boss.

Source: Personal File, 2011

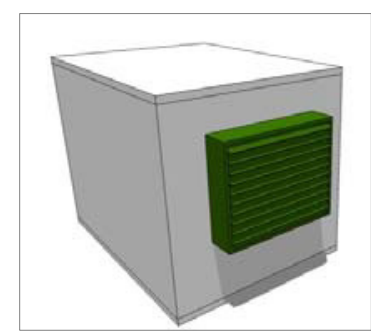

Figure 9: Model 06 - Boss rectangular with the addition of horizontal louvers furniture. Source: Personal File, 2011.

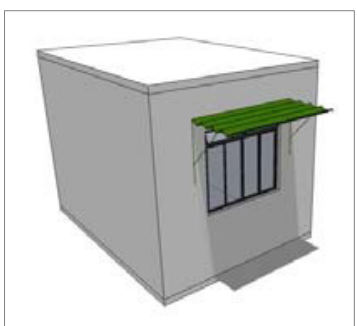

Figure 10: Model 07 - Toldo malleable. Source: Personal File, 2011.

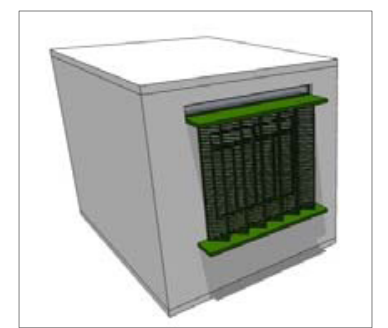

Figure 11: Model 08 - Boss simple (upper and lower) lattice with vertical louvers. Source: Personal archive. 2011
Finally, it is expected that this work contributes towards directing the studies for the improvement of techniques and tools of passive strategies in the context of energy efficiency, more specifically with the use of solar shades and control of sunlight measured in more flexible and malleable to achieve greater variability of situations in tropical regions.

Thus, the flexible solar shades serve as an important factor that can add value to architectural projects and contribute to reducing environmental impact, improving the quality of work and health of employees.

\section{References}

[1] CIB Task Group. TG66 - Energy and the Built Environment. Proceedings. 18th CIB World Building Congress. CIB Publication 355. Salford Quays, United Kingdom, 2010.

[2] David, M; Donn, M; Garce, F; Lenoir, A. Assessment of the thermal and visual efficiency of solar shades. University of La Reunion, Reunion Island, France. In: Building and Environment, 46. 2011.

[3] Miles, Angela K., Perrewé, Pamela L. The Relationship Between Person-Environment Fit, Control, and Strain: The Role of Ergonomic Work Design and Training.. School of Business and Economics, North Carolina A\&T State University. 2011.

[4] Press S; Torcellini P; Shelton D. Using an Energy Performance Based Design-Build Process to Procure a Large Scale LowEnergy Building. National Renewable Energy Laboratory. Las Vegas, Nevada, 2011.

[5] Schellen. L et al., M. Differences between passive and active cooling systems in gender, physiological responses, thermal sensation and productivity. University of Technology, Department of Architecture Building and Planning, Netherlands, 2011 